\title{
sciendo
}

CIVIL AND ENVIRONMENTAL ENGINEERING REPORTS

E-ISSN 2450-8594

CEER 2020; 30 (4): 0111-0124

DOI: $10.2478 /$ ceer-2020-0054

Original Research Article

\section{TEST OF VIBRATIONS INFLUENCE ON THE MEASUREMENT ACCURACY IN THE PRECISE DIGITAL LEVELLER TRIMBLE DINI 03 AND COMPARISON OF ITS VIBRATION SENSITIVITY WITH LEVELLER NI 002}

\author{
Marek KURNATOWSKI ${ }^{1}$ \\ West Pomeranian University of Technology Szczecin, Poland
}

\begin{abstract}
The article presents findings from research on the effect of vibrations on the accuracy of measurement with an automatic precise digital leveller. A special research station was created to induce vibrations on a leveller and to measure vibration parameters that affect staff reading. It contains description of discovered relationship between the vibration parameters and the mean error of a single height difference measurement. The range of frequencies for which the measurement was possible was estimated. The reliability of the measured values obtained under specific vibration conditions was also analysed. The results of current research were compared with similar studies on analogue leveller $\mathrm{Ni}$ 002. The conclusions described in this paper can be helpful in engineering measurements under adverse conditions of ambient vibrations.
\end{abstract}

Keywords: vibrations, measurement accuracy, precise levelling

\section{INTRODUCTION}

Measurements of vertical displacements with precise levellers are the most popular method of estimating earth surface changes taking place over large areas, as well as settlement of buildings and machines $[2,5,10,11,12]$. It has been decades

\footnotetext{
${ }^{1}$ Corresponding author: West Pomeranian University of Technology Szczecin, Poland, e-mail: marek.kurnatowski@zut.edu.pl
} 
since using compensators for precise levelling of lines of sight in automatic levellers became a standard [3,7]. Most of devices are digital levellers performing automatic staff reading, using CCD technology to read unique barcode. The measurement conditions, however, have a different effect on the feasibility and accuracy of the measurement, depending on the equipment used and the variability of the parameters of these conditions [4]. Examples of factors affecting the accuracy of measurements are, among others temperature changes, uneven sunlight, wind pressure and vibrations of external devices transmitting to the leveller. The optical structures of the compensators are very sensitive to such vibrations, which results either in the lack of the possibility of measurements at all, or in reduction in the quality of these measurements, by reducing their accuracy or reliability. Such situations take place in everyday engineering works. The need to measure vertical displacements often concerns objects where occurring vibrations can affect the leveller's operation. Precise levelling is performed on construction sites where heavy equipment and construction machines generate vibrations, during monitoring of engineering structures under heavy traffic conditions, and finally during measurements of industrial machinery and equipment, where the tested machines are often the source of vibrations. Since compensators are most often systems of pendulums, they can be easily brought out of balance by surrounding vibrations. People performing precise levelling should be aware of the equipment limitations due to vibrations, especially since it is mostly impossible to stop the processes generating these vibrations [9].

\section{TEST STAND AND MEASUREMENT CONDITIONS}

The research results presented in this paper are a continuation of the work described in the article by Kurnatowski [8]. In the current part of the research, an experiment was carried out to determine the effect of vibration frequency on the Trimble Dini 03 digital level, including the measurement of the amplitude with a vibrometer. The leveller was tested with the same test stand that was used to test the Ni002 level [8]. A standard wooden tripod was equipped with an $80 \mathrm{~W}$ modelling motor with an eccentrically mounted weight (Fig. 1). As in the previous tests, the weight of the aluminium disc was $7 \mathrm{~g}$, the diameter was $25 \mathrm{~mm}$, and the eccentricity was $5 \mathrm{~mm}$. Also, the same tripod was used as during the Ni002 leveller test. During the test leveller vibrations were generated by an eccentrically rotating mass. Vibration frequency values were set with a potentiometer with an accuracy of about 15 rounds per minute, which corresponds to $0,25 \mathrm{~Hz}$ frequency. The rotating mass constantly make the compensator tremble, reducing its ability to stabilize quickly [3]. The measurement of the rotation speed, and therefore the frequency of vibrations, was performed with a factory calibrated optical tachometer Testo 465.Earlier studies [8] showed that for this test stand the natural 
vibration frequency of the leveller is the same as the motor rotation frequency. The vibratory source is not a point source in reality [9], but this research focus on vibration parameters of the leveller, not vibration sources. Measurement of the leveller's displacements caused by vibrations was taken with the Extech VB450 vibrometer in three axes of the level. The $X$ axis coincided with the line of sight of the leveller, the $Y$ axis was perpendicular to the $X$ axis in the horizontal plane, the $Z$ axis coincided with the vertical direction (Fig. 2).

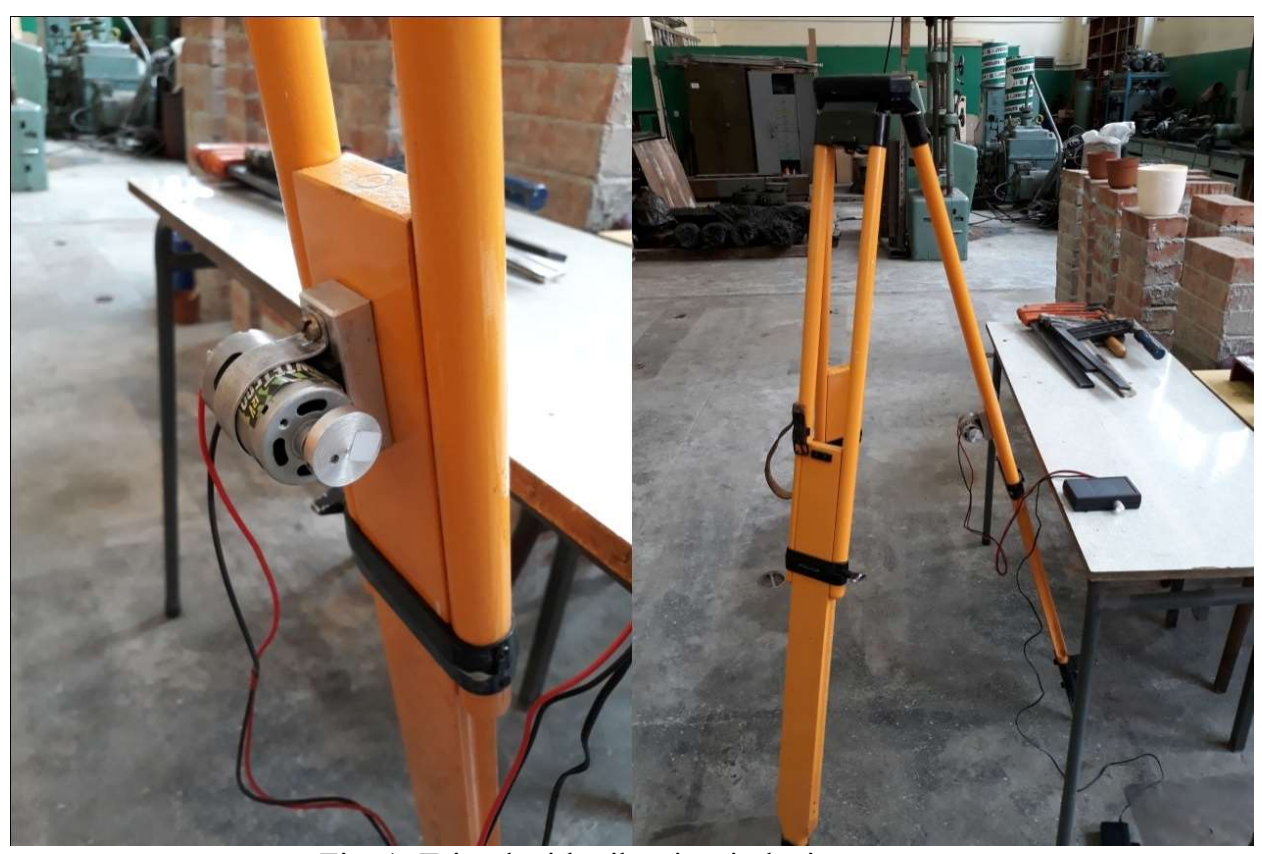

Fig. 1. Tripod with vibration-inducing motor

When the face value of motor's rotation frequency was steady, the height difference between two benchmarks was measured. The measurement took place in the main hall of laboratory of the Faculty of Civil and Environmental Engineering of the West Pomeranian University of Technology in Szczecin, Poland. The same measurement conditions were maintained as in the case of the test of Ni 002 level [8]. The indoor test stand excluded factors that affect the measurement, such as wind pressure, temperature and sunlight variability, or vibrations caused by city traffic. The leveller station was placed between two benchmarks, with equal distances to each staff. The distance to each staff was about $16.5 \mathrm{~m}, \pm 0.05 \mathrm{~m}$, which was about half the maximum distance for precise levelling [3]. As in the previous measurements, the axis of the motor was directed perpendicularly to directions to both staffs. The effect of changes in the length of 
the tripod legs on the leveller's sensitivity to vibration was not investigated. Changing length of the tripod legs was performed in a small $5 \mathrm{~cm}$ range in order to exclude the influence of the stiffness variation on the ability to transmit vibrations to the leveller.

\section{EFFECT OF VIBRATIONS ON STAFF READINGS}

Readings from code staffs are performed automatically, there is no subjective visual judgment of the observer. There is no human factor affecting the accuracy of digital staff reading. Measurement is possible only when the leveller software is capable to compare unambiguously the section of the observed staff with the pattern. Otherwise, the message that reading is not possible is displayed. The staff cannot be read when the staff image is too blurry to clearly indicate which section is in the field of view of the lens. There were many cases when the instrument took a measurement for a given frequency, only to display a message about the lack of such possibility a moment later. These situations mainly concerned the cases of measurements for frequencies at the boundaries of the ranges in which the measurement was possible.

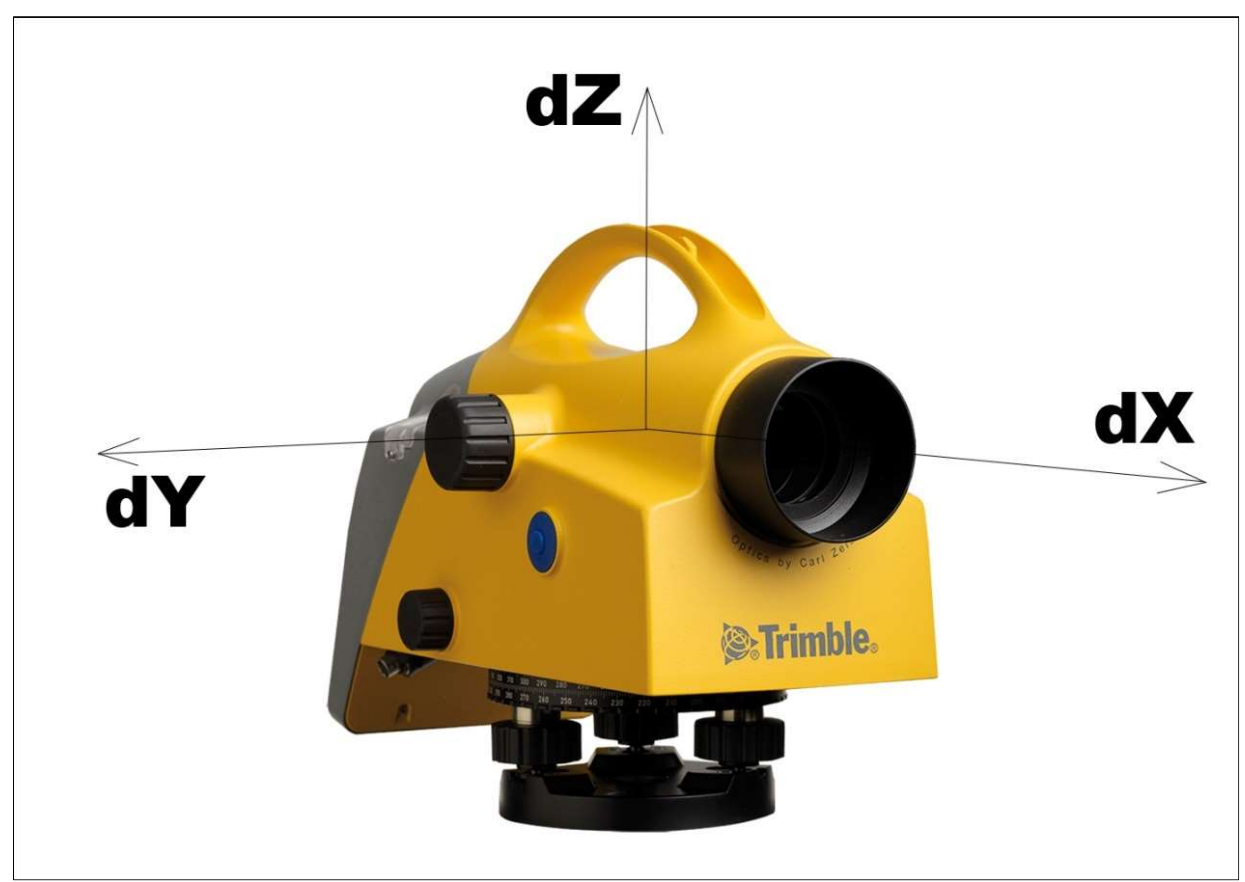

Fig. 2. Graphical interpretation of the directions of the measured leveller's displacements 
Regarding digital instruments, there is one important measurement parameter, which is not found in analogue instruments. Observer can select the number of measurements on the staff per one reading. The instrument performs a given number of measurements and gives back the average value as the result. In analogue instruments it corresponds to a situation where the observer fits the wedge of the crosshairs into the proper staff line several times with a micrometer[6]. Usually, there is no need to use more than triple measurement, therefore studies were carried out for two variants - single and triple measurement. The Dini03 leveller turned out to be partially sensitive to different frequency ranges than the Ni002 analogue leveller. For lower frequencies, the digital device showed a similar sensitivity to vibrations as Ni002 - both models were able to perform measurements for frequencies $0-15 \mathrm{~Hz}$. For higher frequencies, these ranges are different for both models. While Ni002 can perform at frequencies 37 $-43 \mathrm{~Hz}$, Dini03 is usable from as low as $24 \mathrm{~Hz}$. The limit, however, is $38.5 \mathrm{~Hz}$, when the measurement is difficult, but not impossible. When $40 \mathrm{~Hz}$ is reached, it is hardly possible to perform any reading. In the range of $24-38.5 \mathrm{~Hz}$ there is a gap - for the range from 33 to $34 \mathrm{~Hz}$ the instrument is not able to measure. It should be noted that for measurements at frequencies at the boundaries of the ranges in which the measurement was possible, the value of the motor rotation frequency should be set very precisely. Small fluctuations of the potentiometer, comparable with the accuracy of frequency setting, may cause a dramatic change in the behaviour of the leveller and, consequently, make the measurement impossible or distort its results.

For each frequency value, the vibration amplitude in three axes was measured, as shown in Fig. 2. The results of displacement measurements may indicate a strong correlation between the deflections in the direction along the line of sight and the possibility of performing the measurement.

\section{CALCULATION OF MEAN ERRORS}

The mean error of the single height difference measurement was calculated from a sample of 30 pairs of back-forwards readings. As in the case of Ni002, the calculated errors do not contain the influence of errors of unequal scaling of the staff graduation as the readings from each staff were taken within the range of about $5 \mathrm{~cm}$ only. Since other external factors were eliminated, it can be concluded that the variability of the obtained mean error values is the result of the variability of the vibration parameters introduced on the leveller. The calculation process was the same as in the case of Ni002, the formula was used [1]:

$$
m_{0}=\sqrt{\frac{[v v]}{n_{\text {nadl }}}}
$$


where: $m_{0}-$ mean error of a single height difference in millimetres, $[v v]-$ sum of corrections squares, i.e. differences between averaged observation and the result of measurement, $n_{\text {nad }}-$ number of additional observations (number of degrees of freedom).Table 1 presents the calculated values of the height differences between two benchmarks $(d h)$ as the average of 30 measurements together with their mean errors $(m d h)$. The values were segregated into the single or triple measurement results and were assigned to the vibration frequencies at which series of measurements were performed.

Table 1. Height differences values and their mean errors

\begin{tabular}{|c|cc|cc|}
\hline $\begin{array}{c}\text { frequency } \\
{[\mathrm{Hz}]}\end{array}$ & \multicolumn{2}{|c|}{ single measurement } & \multicolumn{2}{c|}{ triple measurement } \\
\hline 0 & 0.027 & 128.92 & 0.019 & 128.91 \\
7 & 0.026 & 128.92 & 0.022 & 128.93 \\
10 & 0.026 & 128.92 & 0.021 & 128.94 \\
11 & 0.022 & 128.92 & 0.019 & 128.93 \\
12 & 0.024 & 128.92 & 0.017 & 128.94 \\
13 & 0.033 & 128.92 & 0.018 & 128.93 \\
14 & 0.041 & 128.93 & 0.022 & 128.90 \\
15 & 0.043 & 128.94 & 0.022 & 128.90 \\
\hline 24 & 0.046 & 128.93 & 0.029 & 128.90 \\
26 & 0.032 & 128.91 & 0.027 & 128.92 \\
28 & 0.041 & 128.91 & 0.034 & 128.91 \\
30 & 0.038 & 128.96 & 0.038 & 128.93 \\
32 & 0.076 & 128.95 & 0.039 & 128.92 \\
\hline 35 & 0.997 & 129.78 & 0.251 & 128.98 \\
37 & 0.682 & 129.43 & 0.553 & 129.65 \\
38.5 & 0.383 & 129.69 & 0.363 & 129.76 \\
\hline & & & & \\
\hline
\end{tabular}

The data from the table clearly shows that triple measurement is more accurate than a single one. This is an expected effect, as increasing the number of 
measurements to some extent increases the accuracy of the mean. In the range of $0-15 \mathrm{~Hz}$, the mean error values for triple measurements practically do not differ from each other. In the case of single measurements, a gradual increase in the mean error values can be seen, up to $0.043 \mathrm{~mm}$. This value corresponds to 1.6 of the initial value for measurement without vibrations and almost 2.0 of the lowest calculated value.

For the next continuous frequency range of $24-32 \mathrm{~Hz}$ there is an increase in the error value at the boundary frequencies for a single measurement. In the case of a triple measurement, the error values for individual frequencies are more similar. The third range of $35-38.5 \mathrm{~Hz}$ is characterized by a significant increase in the mean error values, what eliminates this measurement from the precision levelling accuracy class. However, the case of the $35 \mathrm{~Hz}$ frequency is interesting. There is a big difference between the results from a single and triple measurement. While the results of a single reading give the accuracy of engineering levelling, the use of a triple measurement mode significantly improves the accuracy of the measurement. This can be seen both in the calculated mean errors and the measured values of height difference. For a single measurement it is completely unreliable, differing from the other values by more than $0.8 \mathrm{~mm}$.

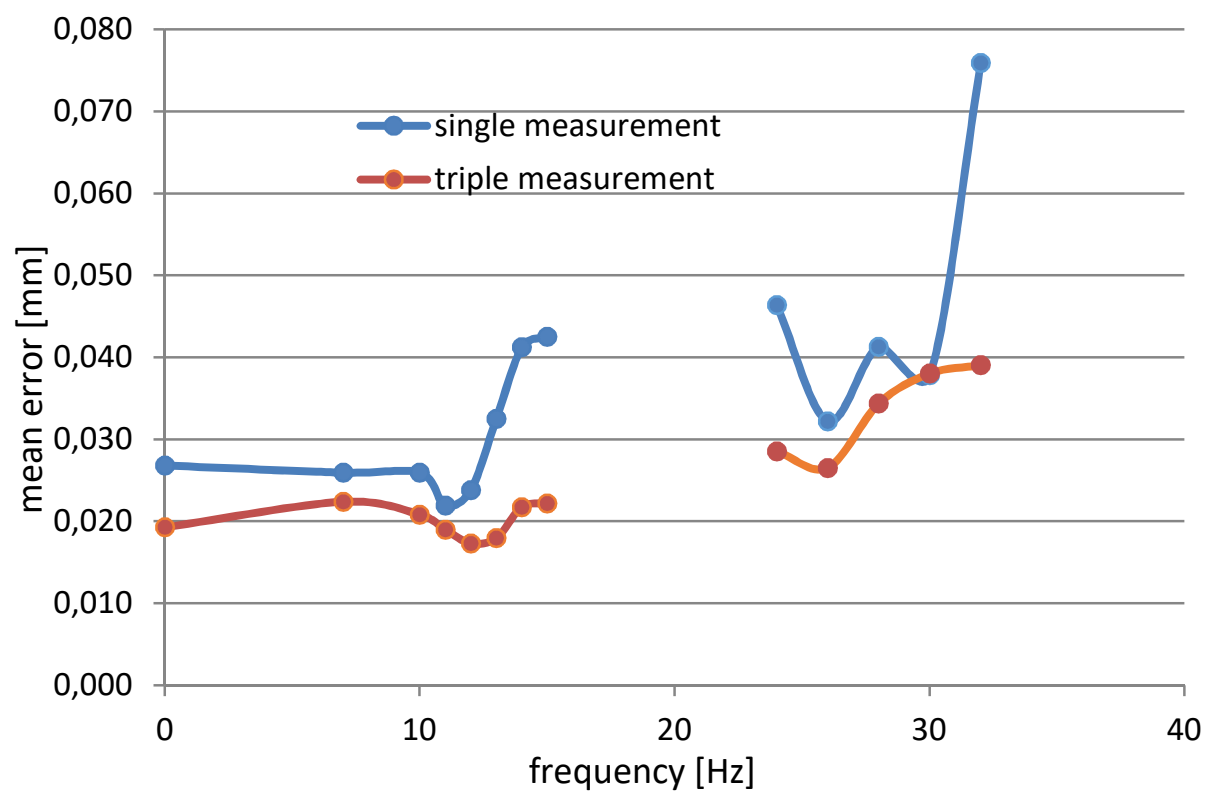

Fig. 3. Dependence of height difference mean errors on the vibration frequency for the Dini 03 leveller in the frequency ranges $0-15 \mathrm{~Hz}$ and $24-32 \mathrm{~Hz}$ 
Fig. 3 shows the dependence of the calculated mean errors of the measured height difference on the leveller's vibration frequency. Only the ranges $0-15 \mathrm{~Hz}$ and 24 $-32 \mathrm{~Hz}$ are included in the graph, as the error values for the range $35-38.5 \mathrm{do}$ not correspond to precise levelling and there is no need to present them in the same scale. It is also worth analysing the values of the difference obtained for individual ranges of frequency. There is a noticeable consistency of these values, which may indicate no systematic errors shifting the staff image. That kind of phenomena could cause a false measurement result. There were situations for $\mathrm{Ni}$ 002 when the mean error value was relatively low, as the 30 measurements were consistent, but the averaged value of the height difference was far from the true value. Obviously, the true value is not known, but it should be assumed that the most reliable estimation of it is the result of measurement without introduced vibrations in triple reading mode.

Fig. 4 shows the values of the differences measured in the triple measurement mode with the confidence interval at the level of $95 \%$. Such a range is defined as $d h \pm 2 m d h$, because with a probability of 0.95 the true value is within this range. The most probable value is marked with a green, dotted line - it was obtained from a triple measurement mode without vibrating the station. This graph confirms that for the $0-15 \mathrm{~Hz}$ and $24-32 \mathrm{~Hz}$ ranges the results of height difference measurement are reliable.

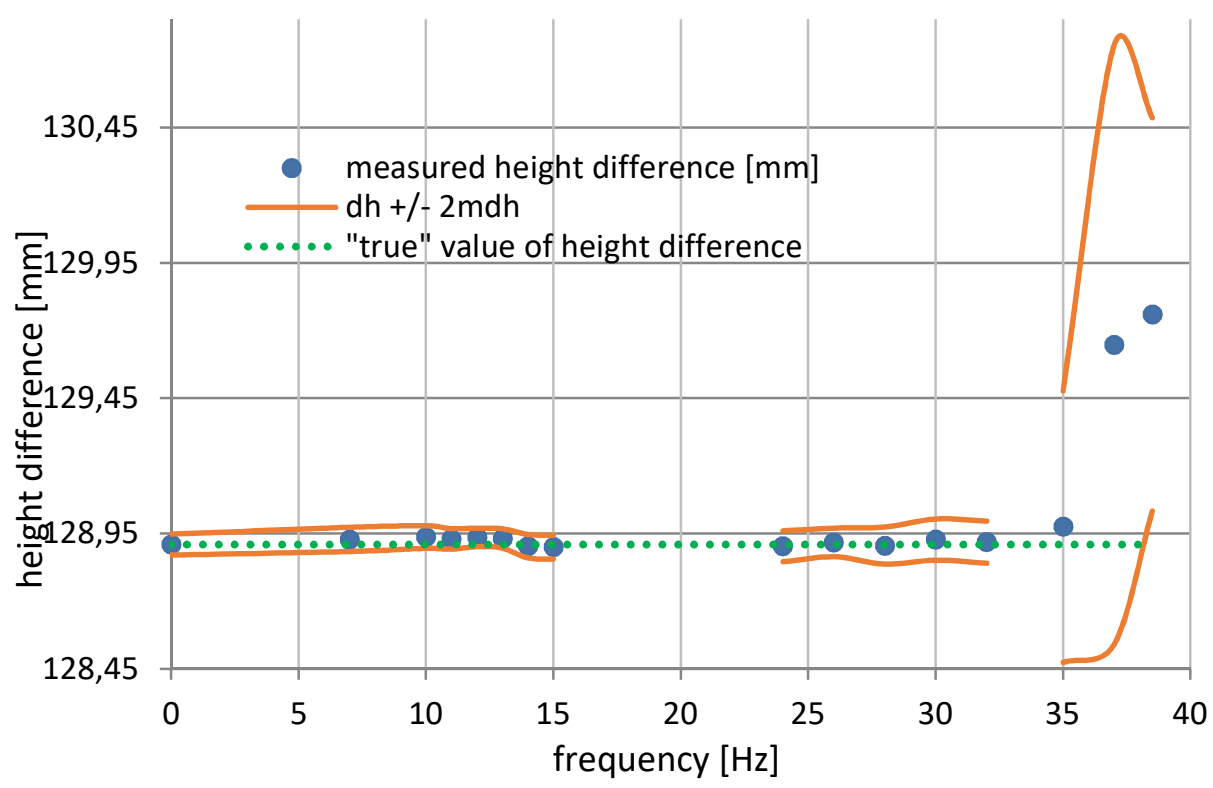

Fig. 4. Comparison of the height difference values obtained at various frequencies with the confidence interval for Dini 03 triple measurement mode 


\section{AMPLITUDE INFLUENCE ON THE MEASURED ERRORS}

The amplitude measurement shows the correlation of the displacements along the line of sight and the ability of taking the measurement. For values $7 \mu \mathrm{m}$ or more the instrument did not take readings at all. However, it is difficult to associate the values of displacements with the values of mean errors of measured height differences. Some cases were observed, when for different values of displacements similar values of mean errors were obtained, and vice versa - for the same values of displacements variable values of mean errors were observed.

Table 2. The values of displacements along individual axes depending on the vibration frequency

\begin{tabular}{|c|c|c|c|c|c|}
\hline $\mathrm{Hz}$ & $d x[\mu \mathrm{m}]$ & $d y[\mu \mathrm{m}]$ & $d z[\mu \mathrm{m}]$ & $\begin{array}{l}\text { mdh single } \\
\text { meas. [mm] }\end{array}$ & $\begin{array}{l}\text { mdh triple } \\
\text { meas. }[\mathrm{mm}]\end{array}$ \\
\hline 0 & 0 & 0 & 0 & 0.027 & 0.019 \\
\hline 7 & 0 & 0 & 0 & 0.026 & 0.022 \\
\hline 10 & 0 & 0 & 0 & 0.026 & 0.021 \\
\hline 11 & 0 & 0 & 0 & 0.022 & 0.019 \\
\hline 12 & 1 & 0 & 0 & 0.024 & 0.017 \\
\hline 13 & 1 & 0 & 0 & 0.033 & 0.018 \\
\hline 14 & 2 & 0 & 0 & 0.041 & 0.022 \\
\hline 15 & 4 & 1 & 1 & 0.043 & 0.022 \\
\hline 16 & 14 & 2 & 2 & - & - \\
\hline 18 & 113 & 35 & 28 & - & - \\
\hline 20 & 32 & 24 & 16 & - & - \\
\hline 22 & 26 & 2 & 15 & - & - \\
\hline 23 & 20 & 5 & 16 & - & - \\
\hline 24 & 3 & 0 & 0 & 0.046 & 0.029 \\
\hline 26 & 5 & 1 & 1 & 0.032 & 0.027 \\
\hline 28 & 5 & 1 & 1 & 0.041 & 0.034 \\
\hline 30 & 5 & 1 & 0 & 0.038 & 0.038 \\
\hline 32 & 5 & 3 & 0 & 0.076 & 0.039 \\
\hline 34 & 7 & 2 & 1 & - & - \\
\hline 35 & 3 & 4 & 1 & 0.997 & 0.251 \\
\hline 37 & 3 & 4 & 2 & 0.682 & 0.553 \\
\hline 38.5 & 4 & 2 & 1 & 0.383 & 0.363 \\
\hline 40 & 10 & 7 & 2 & - & - \\
\hline 41,5 & 14 & 8 & 2 & - & - \\
\hline 43 & 14 & 6 & 2 & - & - \\
\hline
\end{tabular}

It is also difficult to assess which direction of the displacement has the greatest impact on the work of the leveller. An indication may be the fact that the 
instrument refused to measure at high values of the displacement along the line of sight, while the displacements along other axes did not exceed $2 \mu \mathrm{m}$. This means that the displacements along the line of sight determine the ability of staff reading but it is not known whether other directions have the same impact. It was not possible to increase the $Y$ and $Z$ displacement values to the higher level than the ones along $X$ axis. However, considering the compensator's construction, it can be assumed that $X$ is the decisive direction. Possible deviations of the line of sight from the horizontal plane are most easily caused by displacement of the compensator along this axis. In view of the above, when considering the effect of vibrations on the accuracy of levellers, pairs of both quantities - both frequency and amplitude must be considered.

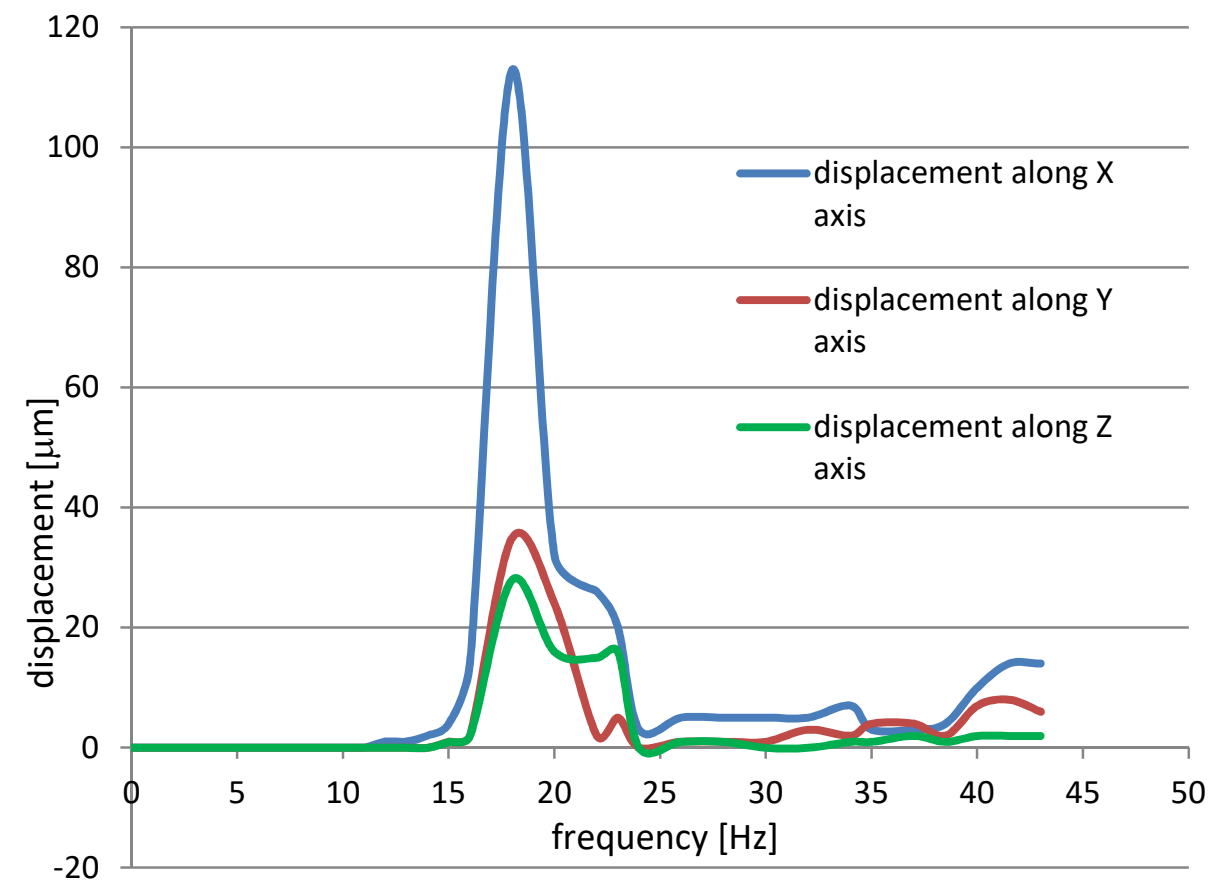

Fig. 5. Distribution of the displacements of the Dini 03 leveller in three axes depending on the vibration frequency

Table 2 presents the values of the leveller's displacement along three perpendicular axes for selected vibration frequencies. Results for ranges for which the measurement with Dini 03 was not possible are marked in orange. In addition, the table was supplemented with mean errors of the measured with Dini 03 height difference. The above data shows that high displacement values are not the only factor that make it impossible to measure with a digital instrument. The data for 
the frequency range of $35-38.5 \mathrm{~Hz}$ also show that, despite the small amplitudes, the result is unreliable. This means that when analysing the influence of vibrations to the accuracy of the measurement, both parameters should be taken into account - the frequency and the amplitude of vibrations. The amplitude data in Table 2 are shown in the graph in Fig. 5. For frequency ranges at which measurement is not possible the value of displacements in all three axes increases.

\section{COMPARISION OF LEVELLERS NI 002 AND DINI 03}

Fig. 6 shows the mean errors obtained with Dini 03 against the results of Ni 002. For most frequency ranges, Dini03 is more favourable, but for higher frequencies $37-43 \mathrm{~Hz}$ the situation is reversed. This means that the Ni 002 leveller should be used at vibration frequencies above $37 \mathrm{~Hz}$.

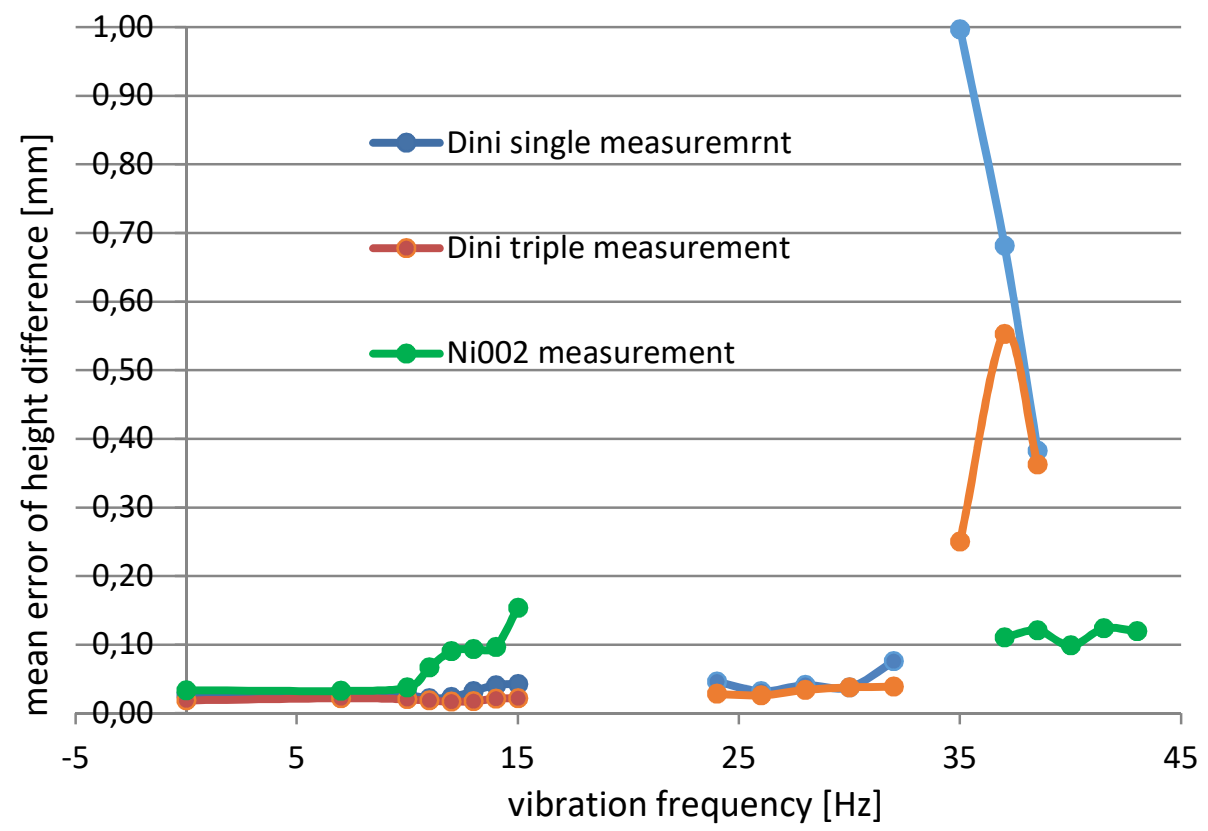

Fig. 6. Comparison of the mean error values of Ni 002 and Dini 03 depending on the vibration frequency

Fig. 7 presents a comparison of the deviations of the measurement results of the height difference from their most probable value. The "true" value was the height difference obtained by measuring without the imposed vibrations. For Dini 03 it was assumed that true value is the average of the triple measurement mode as more reliable. These data visualization shows the credibility of the obtained 
results, since a significant number of deviation values are close to zero, which means that the average of 30 measurements is a value close to the true height difference. It is also interesting that most of the height difference is greater than the most reliable value. This may indicate some systematic error with only one, or both staffs but with opposite sign for each. If the error applied to both staffs to the same degree, it would have a chance to be reduced since the height difference is the difference in staff readings.

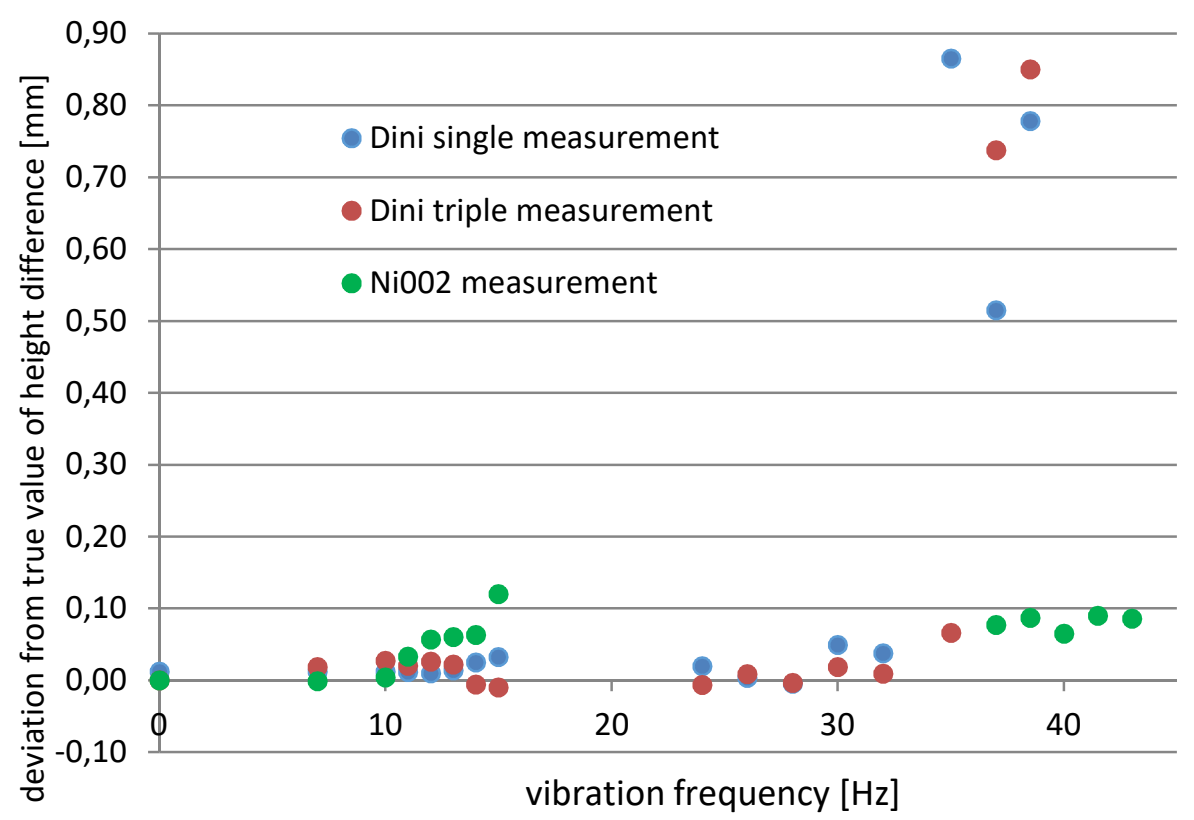

Fig. 7. Deviations of the height difference measurement results from their most probable value

\section{SUMMARY}

The research on the vibrations influence on the accuracy of precision levelling has been extended by testing a digital level on the example of Trimble Dini 03. This leveller is sensitive to vibrations in different frequency ranges than the previously tested analogue Ni 002 model. The ranges of vibration frequencies in which the leveller is able to make a reading and mean errors of measured height differences were estimated. Dini 03 can perform in the frequency ranges $0-15 \mathrm{~Hz}$ and $24-$ $32 \mathrm{~Hz}$ and the obtained results fall within the precision levelling accuracy class. The leveller can measure for higher frequencies, $35-38,5 \mathrm{~Hz}$, but the results are 
not reliable, as evidenced by both the high mean error and the false value of the measured height difference. This is not enough to place the measurement in the precision levelling category. On the other hand, the Ni 002 leveller is not able to make readings for the $24-32 \mathrm{~Hz}$ range, but it does much better at frequencies above $37 \mathrm{~Hz}$. The value of the vibration amplitude for the given frequencies for the digital leveller was also measured and the impact of its value on the measurement possibility was estimated.

\section{CONCLUSIONS AND INDICATIONS TO FURTHER RESEARCH}

One of the observations from the research is the higher accuracy of triple measurement mode compared to single readings mode. While this phenomenon is obvious for measurements performed in steady conditions, the tests also confirmed this rule for vibrations imposed on the leveller. This improvement is especially visible for frequencies at the boundaries of the ranges in which the measurement is possible.

The results of amplitude measurement indicate that the $7 \mu \mathrm{m}$ displacement along the line of sight makes it impossible to stabilize the compensator enough to read from the staff. Thus, the amplitude may determine the ability to take a measurement, but its lower values do not translate into the accuracy of the measurement directly. It is suspected that the direction of the vibrating leveller displacement along the line of sight is of key importance for the feasibility of measurements. When analysing the influence of vibrations to the accuracy of the measurement, both parameters should be considered in pairs - the frequency and the amplitude of vibrations.

Future research should determine which direction of the displacement is crucial for the accuracy of the measurement. For this purpose, the vibration inducing system should be redesigned in such a way that the displacement component along the line of sight is not dominant. The number of the analysed pairs of vibration parameters should also be increased by changing the mass of the weight on the motor or its eccentricity. Another variable may be the length of the tripod legs they probably resonate differently, depending on their length and stiffness.

\section{REFERENCES}

1. Adamczewski, Z 2004. Rachunek wyrównawczy w 15 wyktadach. Warszawa: Oficyna Wydawnicza Politechniki Warszawskiej. 
2. Amighpey, M, Voosoghi, B and Arabi, S 2016. Modeling interseismic deformation field of North Tehran Fault extracted from precise leveling observation. Tectonophysics 679, 169-179.

3. Baran, W et al. 1993. Niwelacja precyzyjna. Warszawa: Polskie Przedsiębiorstwo Wydawnictw Kartograficznych im. E. Romera.

4. Gawronek, P, Makuch, M, Mitka, B and Gargula, T 2019. Measurements of the vertical displacements of a railway bridge using TLS technology in the context of the upgrade of the polish railway transport. Sensors 19 (19), 4275.

5. Gu, Y, Hsu, L and Kamijo, S 2018. Towards lane-level traffic monitoring in urban environment using precise probe vehicle data derived from threedimensional map aided differential GNSS. IATSS Research 42 (4), 248-258.

6. Hermanowski, A 1993. Pomiary przemieszczeń pionowych. Warszawa: Instytut Geodezji i Kartografii.

7. Kuchmister, J, Gołuch, P, Ćmielewski, K, Rzepka, J and Budzyń, G 2020. A functional-precision analysis of the Vertical Comparator for the Calibration of geodetic Levelling Systems. Measurement 163, 107951.

8. Kurnatowski, M 2018. Test of Impact of Vibrations Frequency on Mean Errors of the Precise Height Differences Measurement with Analogue Automatic Leveller NI002. Civil and Environmental Engineering Reports $\mathbf{2 8}$ (4), 129-137.

9. Mak, CM and Yun, Y 2010. A study of power transmissibility for the vibration isolation of coherent vibratory machines on the floor of a building. Applied Acoustics 71 (4), 368-372.

10. Mrówczyńska, M, Sztubecki, J and Greinert, A 2020. Compression of results of geodetic displacement measurements using the PCA method and neural networks. Measurement: Journal of the International Measurement Confederation 158, 107693.

11. Murase, M, Matta, N, Lin, Ch, Chen, W and Koizumi, N 2013. An episodic creep-slip event detected by precise levelling surveys in the central part of the Longitudinal Valley Fault, eastern Taiwan, in 2011-2012. Tectonophysics 608, 904-913.

12. Skrzypczak, I, Kokoszka, W, Kogut, J and Oleniacz, G. 2017. Methods of Measuring and Mapping of Landslide Areas, IOP Conference Series: Earth and Environmental Science 95 (2), 022013.

Editor received the manuscript: 20.11.2020 